\title{
Adaptação da Escala de Autoabsorção para Adultos Brasileiros
}

\author{
Amanda da Costa da Silveira*, Thiago Gomes de Castro, \& William Barbosa Gomes \\ Universidade Federal do Rio Grande do Sul, Porto Alegre, Brasil
}

\begin{abstract}
RESUMO
Autoabsorção é definida como perseveração excessiva da atenção que o indivíduo destina às suas reflexões internas. A Escala de Autoabsorção (EAA) propõe mensurar essa faceta negativa e desconstrutiva da autoconsciência humana e distinguir se seu foco está voltado para aspectos públicos ou privados. O objetivo desse estudo foi adaptar a EAA para o Brasil e reunir evidências de validade fatorial e convergente. Setecentos e vinte e dois brasileiros adultos responderam a versão traduzida da EAA, a Escala de Autoconsciência (EAC) e o Questionário de Ruminação e Reflexão (QRR). Análise fatorial indicou a presença de duas dimensões (autoabsorção privada e autoabsorção pública). A versão brasileira da EAA apresentou validade fatorial e convergente satisfatórias, podendo ser utilizada em pesquisas futuras no Brasil.
\end{abstract}

Palavras-chave: autoconsciência; autoabsorção; ruminação; psicometria; adaptação.

\begin{abstract}
Adaptation of the Self-absorption Scale to Brazilian Adults

Self-absorption is defined as an excessive perseveration of attention that one displays toward their own reflections. The Self-Absorption Scale (SAS) measures this negative deconstructive dimension of self-consciousness and distinguishes whether its focus is related to private or public aspects of oneself. The objective of this study was to adapt the SAS to Brazil and to gather evidences of factorial and convergent validity for the Scale. Seven hundred and twenty two Brazilian adults answered the translated version of SAS, the Self-Consciousness Scale (SCS), and the Rumination-Reflection Questionnaire (RRQ). Factor analysis revealed two main components (private and public selfabsorption). The adapted SAS fulfilled expectations concerning factorial and convergent validity. It can be used in future research in Brazil.
\end{abstract}

Keywords: self-consciousness; self-absorption; rumination; psychometrics; adaptation.

A psicologia tem entendido o fenômeno da autoconsciência enquanto um traço de personalidade que encerra a disposição natural humana de focar os pensamentos para dentro de si mesmo. Segundo esta concepção, a autoconsciência apresenta níveis de atenção direcionada a si mesmo enquanto uma capacidade adaptativa do organismo. Assim, alguns indivíduos tendem a refletir sobre si mesmos de forma mais intensa e/ou mais frequente do que outros, e isso seria uma característica relativamente estável e transsituacional em suas vidas (Zanon \& Teixeira, 2006).
Buscando avaliar as diferenças individuais deste traço de personalidade, pesquisadores norte-americanos construíram em 1975 a Escala de Autoconsciência (EAC) (Fenigstein, Scheier, \& Buss, 1975), cujo interesse repousa na dinâmica do foco atencional em situações reflexivas cotidianas. Nesse primeiro momento em que a EAC fora desenvolvida, a operacionalização da autoconsciência restringia-se a uma distinção entre a atenção que o indivíduo direciona para dentro de si e a atenção direcionada para fora de si. Além desses dois polos, a EAC também mensura o impacto da autorreflexão quando o indivíduo está na

* Endereço para correspondência: Rua Jacicoema, 492, Guarujá, Porto Alegre, RS, CEP 91770-420.

E-mail: amandadacosta@gmail.com. 
presença de outras pessoas. Os autores chamaram estas três instâncias respectivamente de autoconsciência privada, autoconsciência pública e ansiedade social. Essas três dimensões da autoconsciência serão descritas em maior detalhe a seguir.

A subescala de autoconsciência privada diz respeito aos pensamentos e reflexões que o indivíduo tem sobre aspectos particulares dele mesmo. Segundo os próprios autores da EAC (Fenigstein e cols., 1975), esta instância guarda semelhanças com o conceito de introversão tradicionalmente proposto por Carl Gustav Jung em seu livro Tipos Psicológicos, por identificar indivíduos geralmente orientados para seu mundo interno de ideias, quer sejam seus conteúdos "intelectuais" ou "sentimentais" (Jung, 1933/1974, p. 529). Por outro lado, os autores referem que a subescala de autoconsciência pública tem relações diretas com a proposta de George Mead (1934/1962). Segundo este autor, o indivíduo, ao considerar a perspectiva dos outros, vê-se como um objeto social. Assim, essa dimensão da autoconsciência abarcaria o interesse e a preocupação individuais que se tem de si enquanto um estímulo social para os outros.

A subescala de ansiedade social apresenta itens semelhantes aos da autoconsciência pública; contudo, as análises fatoriais realizadas pelos autores reforçaram a necessidade de compor um terceiro fator. Além disso, apenas uma baixa correlação entre ansiedade social e autoconsciência pública fora encontrada. Procurou-se explicar essa relação em dois momentos: inicialmente o indivíduo tomaria consciência de sua imagem pública e, posteriormente, poderia avaliá-la e então tornar-se apreensivo. Dessa forma, a autoconsciência pública seria uma condição necessária para o desenvolvimento da ansiedade social, salientando que nem toda autoconsciência pública pode evoluir para o surgimento de ansiedade social (Fenigstein e cols., 1975).

Diante dessas características da EAC, a escala vem sendo utilizada em diversos contextos, como na clínica (ver, por exemplo, os estudos de Dodge, Hope, Heimberg, \& Becker, 1988; Edelmann, 1990; Ruipérez \& Belloch, 2003; Striegel-Moore, Silberstein, \& Rodin, 1993), e na educação (por exemplo, ver Aamodt \& Keller, 1981; Robinson, Hobbs, Joseph, Robertson, \& Singleton, 2000), em interação com outras variáveis. Além disso, a EAC foi traduzida e validada para diversos idiomas, como o alemão (Hei- nemann, 1979), o Chinês (Shek, 1994), o espanhol (Banos, Belloch, \& Perpina, 1990), o esloveno (Avsec \& Bajec, 2006), o estoniano (Realo \& Allik, 1998), o italiano (Comunian, 1994), o sueco (Nystedt \& Smari, 1989), o turco (Ruganci, 1995), e, inclusive, o português brasileiro (Teixeira \& Gomes, 1995).

De acordo com a teoria original de Duval e Wicklund (1972), que embasa a proposta da EAC, indivíduos com altos níveis de autoconsciência deveriam apresentar maiores índices de autoconhecimento e, por conseguinte, maior adaptação psíquica; ou seja, eles deveriam estar mais satisfeitos com suas vidas e ser psicologicamente mais saudáveis. Contudo, estudos indicaram que observar a si mesmo pode trazer consequências negativas em relação à cognição e ao afeto: ansiedade social tem se mostrado correlacionada a altos níveis de autoconsciência pública e depressão está relacionada a altos níveis de autoconsciência privada (Gibbons, 1990; Ingram, 1990; Mor \& Winquist, 2002). Evidenciou-se também a correlação de autoconsciência privada com neuroticismo (Trapnell \& Campbell, 1999) e baixa autoestima (Watson, Hickman, Morris, Stutz, \& Whiting, 1994). Diante deste panorama, a tendência atual dos estudos em autoconsciência é dividir o construto entre seus aspectos construtivos e destrutivos, como uma tentativa de resolver os contrastes da teoria e dos achados empíricos, que compõem o chamado "paradoxo da autoabsorção" (Zanon \& Teixeira, 2006, p. 81).

Assim, nos últimos dez anos, o desenvolvimento de pesquisas focadas nas consequências comportamentais e cognitivas do processo de autoconsciência promoveu diversas tentativas de refinamento da EAC. Essas tentativas visaram avaliar nuanças do processo não contempladas pela EAC. Um dos focos de refinamento foi, justamente, a dimensão psicopatológica imbricada nas consequências mal adaptativas do processo de focar a atenção em si mesmo (Scandell, 2001). Neste sentido, Ingram (1990) sugeriu que a autoconsciência teria um equivalente pautado pela patologia, o qual ele chamou de autoabsorção, e este construto, por sua vez, varia em três dimensões: grau, duração e flexibilidade. Portanto, a autoabsorção seria, segundo essa abordagem, uma forma de autoconsciência atrelada a psicopatologias e caracterizada pelo excesso, perseveração e rigidez da atenção voltada para as reflexões individuais (McKenzie \& Hoyle, 2008). Consequentemente, com o propósito de avaliar o nível dessa dimensão da autoconsciência mal adap- 
tativa, McKenzie e Hoyle criaram a Self-Absorption Scale (Escala de Autoabsorção - EAA).

Em 1999, Trapnell e Campbell já haviam indicado uma relação entre autoconsciência privada e indicadores de má adaptação psicológica, o que os levou à construção do Questionário de Reflexão e Ruminação (QRR) para acessar duas formas de autoconsciência privada, designadas ruminação e reflexão. O QRR foi traduzido e validado na população universitária brasileira por Zanon e Teixeira (2006). Segundo McKenzie e Hoyle (2008), o conceito de ruminação, tal qual o QRR de Trapnell e Campbell se propõe a avaliar, não contempla as dimensões pública e privada. O QRR fora construído como uma bifurcação somente da subescala de autoconsciência privada. Além disso, outros estudos também indicaram que o conceito de ruminação nem sempre se refere aos conteúdos relativos ao self, como Papageorgiou e Wells (2004) e DaSilveira (2007) propuseram. Desta forma, pode-se ruminar a respeito da questão da fome no Brasil, por exemplo, sem que isso implique uma forma de autoabsorção, pois não embute o indivíduo no objeto dos pensamentos e reflexões. O conceito de autoabsorção, no contexto da EAA, indica a ocorrência da perseveração em pensamentos autorreferidos específicos.

Além do objetivo de mensurar a atenção rígida e excessiva em aspectos individuais, a Escala de Autoabsorção visa a distinguir esse foco quando direcionado aos aspectos públicos e privados do self. Para os autores da EAA, nem o Questionário de Ruminação e Reflexão de Trapnell e Campbell (1999), nem a Escala de Autoconsciência de Fenigstein e cols. (1975) provêem itens que abarcam os interesses da EAA, sobretudo em relação à sua subescala de autoabsorção pública. Saliente-se que essa atenção especial à distinção entre eventos públicos e privados não provém da abordagem da autoconsciência segundo Ingram (1990), que inspirou os autores da EAA a construírem a escala. Trata-se, pois, de um acréscimo à teoria feito por McKenzie e Hoyle (2008), sob a justificativa de que tal distinção tem se mostrado útil para detectar emoções autoconscientes e poderia contribuir na integração do conceito de autoabsorção à vasta literatura existente sobre a temática da autoconsciência em psicopatologia.

Diante dessa importância dada ao conceito de autoabsorção enquanto faceta psicopatológica da autoconsciência e aos inúmeros estudos que tem se benefi- ciado da distinção entre os aspectos públicos e privados da autoconsciência, o objetivo do presente trabalho é realizar a adaptação da Self-Absorption Scale para o Brasil e verificar se a estrutura fatorial do estudo original se mantém.

Os objetivos específicos deste trabalho foram os seguintes: 1) Verificar a validade fatorial da EAA. A hipótese é de que a versão para o português brasileiro também apresenta dois fatores, indicando a divisão entre as dimensões pública e privada da autoabsorção; 2) Verificar o índice de consistência interna da EAA e de suas subescalas, e, para tanto, será utilizado o alpha de Cronbach; 3) Por fim, buscaram-se indícios de validade convergente entre as subescalas da EAA e variáveis teoricamente relacionadas aos construtos. Sendo assim, espera-se encontrar correlação positiva entre autoabsorção pública e autoconsciência pública e ansiedade social (subescalas da EAC), e autoabsorção privada e autoconsciência privada (subescala da EAC); espera-se também encontrar indício de correlação positiva entre ruminação (subescala do QRR) e autoabsorção privada.

\section{MÉTODO}

\section{Tradução e adaptação da escala}

A escala foi primeiramente traduzida do inglês norte-americano para o português brasileiro por dois pesquisadores de forma independente, sendo um deles autor deste trabalho e o outro com conhecimento técnico e ciente dos objetivos da pesquisa. Nesta etapa, enfatizou-se a tradução conceitual e não estritamente literal dos itens da escala. Ambas as traduções foram comparadas e constatou-se que eram mínimos os ajustes para fins de se obter uma única tradução consensual.

Logo após a tradução consensual, um psicólogo norte-americano com fluência na língua portuguesa brasileira e que desconhecia a escala original proferiu uma tradução reversa (back translation) dos itens. Por fim, realizou-se uma revisão por comitê de especialistas para averiguar se a versão traduzida refletia a versão original. O comitê foi composto por três especialistas brasileiros (fluentes em inglês), que compararam as duas versões em inglês (original e tradução do português). Para todos os itens, ao menos dois juízes concordaram com a correspondência de sentido entre a tradução e o original, sugerindo a equivalência semân- 
tica (gramática e vocabulário) e idiomática/conceitual (expressões com sentidos equivalentes) entre os itens.

A versão preliminar do instrumento então passou por um revisor de língua portuguesa e foi aplicada em 20 participantes voluntários, que foram questionados a respeito de possíveis dificuldades encontradas para responder ao instrumento, o que não foi constatado. Sendo assim, a versão final do instrumento foi composta e sua tradução pode ser conferida na Tabela 1 .

Tabela 1

Carga Componencial dos Itens nos Fatores I e II

\begin{tabular}{|c|c|c|}
\hline Item & Fator 1 & Fator 2 \\
\hline \multicolumn{3}{|l|}{ Autoabsorção Privada } \\
\hline 4. Eu penso sobre mim mais do que sobre qualquer outra coisa. & 0,610 & \\
\hline 5. Quando eu tento pensar em outra coisa além de mim, não consigo. & 0,769 & \\
\hline $\begin{array}{l}\text { 6. Quando eu tenho que realizar uma tarefa, eu não a faço tão bem quanto deveria, porque minha } \\
\text { concentração é interrompida com pensamentos sobre mim ao invés da tarefa. }\end{array}$ & 0,760 & \\
\hline 9. Minha mente nunca se foca em algo a não ser em mim, por muito tempo. & 0,761 & \\
\hline 11. Não consigo fazer minha cabeça parar de pensar pensamentos sobre mim mesmo. & 0,736 & \\
\hline $\begin{array}{l}\text { 12. Às vezes estou tão profundamente pensando sobre minha vida que não estou consciente de } \\
\text { meus arredores. }\end{array}$ & 0,556 & \\
\hline $\begin{array}{l}\text { 15. Quando penso sobre a vida, mantenho-me pensando sobre isso por um tempo tão longo que } \\
\text { não consigo direcionar minha atenção para tarefas que precisam ser feitas. }\end{array}$ & 0,636 & \\
\hline \multicolumn{3}{|l|}{ Autoabsorção pública } \\
\hline 1. Eu me pego querendo saber o que os outros pensam de mim mesmo quando não quero. & & 0,726 \\
\hline $\begin{array}{l}\text { 2. Eu tenho dificuldades em me focar no que os outros estão falando, porque gostaria de saber o } \\
\text { que eles estão pensando de mim. }\end{array}$ & & 0,582 \\
\hline 3. Eu pressinto que os outros estão constantemente me avaliando quando estou com eles. & & 0,669 \\
\hline 7. Eu gostaria de que os outros não fossem tão críticos sobre mim como eles são. & & 0,520 \\
\hline 8. Eu estou muito ciente do que os outros pensam de mim, e isso me incomoda. & & 0,523 \\
\hline 10. Quando eu começo a pensar sobre como os outros me veem, eu fico agitado. & & 0,645 \\
\hline 13. Desaponta-me quando as pessoas que encontro não gostam de mim. & & 0,619 \\
\hline $\begin{array}{l}\text { 16. Quando eu estou para encontrar alguém pela primeira vez, me preocupa saber se essa pessoa } \\
\text { vai gostar de mim. }\end{array}$ & & 0,696 \\
\hline $\begin{array}{l}\text { 17. Depois de estar entre outras pessoas, eu penso sobre o que eu deveria ter feito diferente } \\
\text { quando eu estava com elas. }\end{array}$ & & 0,690 \\
\hline
\end{tabular}

Nota. São exibidas apenas as cargas de valor superiores a 0,35.

\section{Participantes}

O instrumento foi aplicado a uma amostra de conveniência de 722 adultos brasileiros predominantemente das regiões sul e sudeste do país (respectivamente $69 \%$ e $19 \%$ dos respondentes). O nordeste bra- sileiro teve uma representatividade de $4 \%$ da amostra, a região centro-oeste $1 \%$ e o norte brasileiro contou com menos de $1 \%$ da amostra. Além disso, $4 \%$ dos respondentes estavam residindo no exterior no momento da pesquisa. A idade média dos respondentes foi de 30 anos ( $\mathrm{DP}=4,63$ ), sendo 60,8\% mulheres. Do total de participantes, 38,4\% eram alunos de pós- 
graduação, 29,3\% estavam cursando o ensino superior, $26,7 \%$ possuíam o ensino superior completo e $5,5 \%$ cursaram até o ensino médio. $\mathrm{O}$ restante dos participantes $(4,8 \%)$ não informou sua escolaridade.

\section{Instrumentos}

Um breve protocolo requisitando dados demográficos foi apresentado aos participantes, em que se perguntava o sexo, a idade, o grau de instrução (e, no caso de curso superior, a especificação do mesmo) e a unidade federativa de residência do respondente. Além disso, foram utilizados três instrumentos psicológicos: a Escala de Autoabsorção, cuja adaptação é o objeto dessa pesquisa; e, para fins de verificar a validade convergente das subescalas, utilizaram-se as versões brasileiras da Escala de Autoconsciência, e o Questionário de Ruminação e Reflexão. Os três instrumentos de autorrelato são descritos a seguir.

Escala de Autoabsorção (EAA): a escala, traduzida para o português brasileiro, consta de 17 itens, compostos por sentenças pessoais e afirmativas por exemplo, "Depois de estar entre outras pessoas, eu penso sobre o que deveria ter feito diferente quando eu estava com elas", para a dimensão pública da autoabsorção, e "Quando eu tenho que realizar uma tarefa, eu não a faço tão bem como deveria porque minha concentração é interrompida com pensamentos sobre mim ao invés da tarefa", para a dimensão privada da autoabsorção. Para que os participantes indicassem o quanto se identificavam com as afirmações constantes nos itens, foi utilizada uma escala do tipo Likert de cinco pontos, em que " 0 " representa "nada característico" e "4" "extremamente característico".

Escala de autoconsciência revisada (EAC-R) (Scheier \& Carver, 1985): a Escala foi elaborada a partir de revisão empreendida na escala original EAC (Fenigstein \& cols., 1975). É composta por 22 itens com escala tipo Likert de cinco pontos, em que " 0 " representa "nada característico" e " 4 " "extremamente característico". O instrumento é composto por uma estrutura trifatorial, a saber: autoconsciência privada (com nove itens, por exemplo: "Eu estou sempre tentando me entender"), autoconsciência pública (com sete itens, por exemplo: "Eu me preocupo com a maneira como me apresento"), e ansiedade social (com seis itens, por exemplo: "É difícil para mim trabalhar quando há alguém me olhando"). A versão adotada na pesquisa foi a traduzida e validada para a população brasileira por Teixeira e Gomes (1995). Esta versão, além de obter uma confiabilidade aceitável $(0,73$ para coeficiente de alpha, e 0,89 para teste-reteste), confirmou a estrutura tri-fatorial constatada na versão original.

Questionário de Ruminação e Reflexão (QRR) (Trapnell \& Campbell, 1999): questionário que visa acessar duas formas de autoconsciência privada: autorreflexão (self-reflection) e autorruminação (selfrumination). Consiste em um questionário composto por 24 itens. Metade dos itens refere-se a sentenças de autorreflexividade, por exemplo, "Eu adoro analisar por que eu faço as coisas" e a outra metade dos itens está relacionada à autorruminação, como "Minha atenção está frequentemente focada em aspectos sobre mim sobre os quais eu gostaria de parar de pensar". Este questionário já foi traduzido e adaptado para a população brasileira por Zanon e Teixeira (2006). A versão brasileira obteve bom índice de confiabilidade (0,87 para coeficiente de alpha, ), e confirmou a estrutura bifatorial constatada na versão original.

\section{Procedimentos}

Os participantes foram recrutados a partir de convites enviados por correio eletrônico à rede de contatos do grupo de pesquisa dos autores. Os destinatários eram convidados a responder a pesquisa e a sugerir o convite para seus conhecidos que se enquadrassem nos requisitos da pesquisa (ter acima de 18 anos e ser brasileiro), seguindo, assim, a técnica de amostragem de bola-de-neve.

Os instrumentos, todos autoadministráveis, foram disponibilizados na internet através de um sítio atrelado à Universidade e ao sistema de coleta de dados online provido pela empresa Qualtrics (www.qual trics.com). O tempo médio para respondê-los foi de aproximadamente 15 minutos. Antes de responder os instrumentos, os participantes eram solicitados a ler o Termo de Consentimento Livre e Esclarecido e, ao final, em caso de concordância, seriam redirecionados para o preenchimento dos mesmos. O sistema do servidor Qualtrics encarregou-se de disponibilizar de forma aleatória a apresentação sequencial das três escalas (EAA, EAC-R e QRR), logo após o preenchimento dos dados demográficos por cada participante. Ao final do preenchimento, os participantes eram redirecionados a uma tela de agradecimento e encer- 
ravam-se suas respectivas sessões de coleta de dados. O estudo foi previamente aprovado pelo Comitê de Ética em Pesquisa dao Instituto de Psicologia da Universidade Federal do Rio Grande do Sul (UFRGS).

\section{Análise dos dados}

Para se verificar a validade fatorial da EAA, realizou-se a análise fatorial exploratória do instrumento, optando-se por um método de extração por componentes principais, com rotação Varimax, tendo em vista que a teoria indica independência entre os fatores avaliados pela escala. Para avaliar a fidedignidade, utilizou-se o índice de consistência interna alpha de Cronbach. Correlações de Pearson foram utilizadas na análise das interações entre as subescalas da EAA e demais variáveis avaliadas.

\section{RESULTADOS}

\section{Análise dos fatores da EAA e fidedignidade das subescalas}

O método de Kaiser-Meyer-Olkin (KMO) foi utilizado como medida de adequação dos dados da amos- tra para a análise e apresentou resultado de 0,900, o que possibilita a explicação de uma boa quantidade de variância. Outro parâmetro utilizado para inferir a adequação da matriz para a extração dos fatores foi o teste de esfericidade de Bartlett, o qual também apresentou resultado significativo $\left(\mathrm{X}^{2}=4393,62, \mathrm{gl}=136 \mathrm{e}\right.$ $\mathrm{p}<0,001)$.

O scree plot também foi consultado para uma aproximação do número de fatores, uma vez que três fatores alcançaram autovalores maiores que 1 . Os três fatores alcançaram uma variância explicada acumulada de 53,67\%; sendo que o primeiro fator explicou $24,32 \%$ da variância, o segundo, $22,10 \%$ e o terceiro, $7,24 \%$. Entretanto, o scree plot distinguiu dois fatores (ver Figura 1). Além disso, a matriz rotada dos componentes evidenciou que o terceiro fator carregou unicamente no item 14 da escala ("Eu não perco grandes quantidades de tempo pensando sobre mim mesmo"). Outros dois itens que também carregaram no terceiro fator (itens 7, "Eu gostaria de que os outros não fossem tão críticos sobre mim como eles são", e 8, "Eu estou muito ciente do que os outros pensam de mim, e isso me incomoda") apresentaram cargas muito semelhantes nos outros dois fatores.

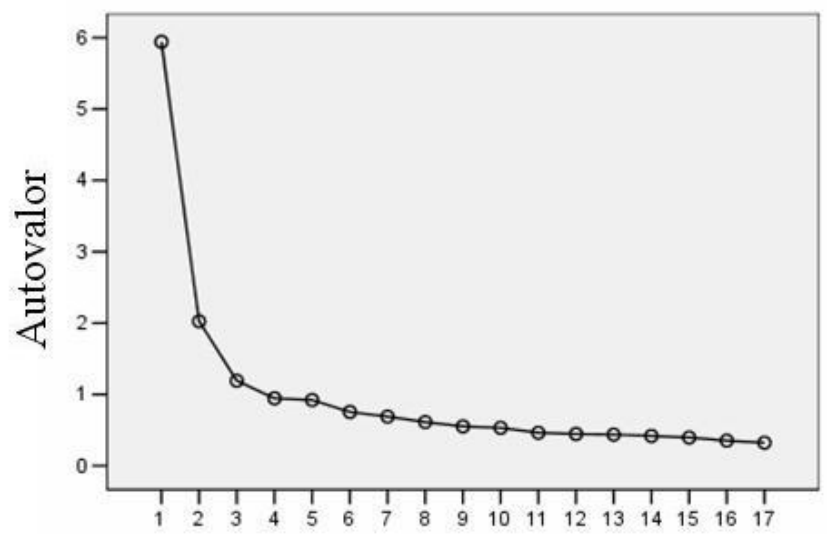

Figura 1. Scree plot distinguindo dois fatores.

Seguindo o scree plot e considerando a fragilidade do terceiro fator, uma análise fatorial com base na imposição da extração de dois fatores foi realizada. A variância explicada acumulada obtida foi de 46,68\% e pode ser considerada satisfatória. Em observação à tabela de comunalidades, o item 14 apresentou um índice de 0,13 , ao passo que os demais itens da escala apresentaram comunalidades acima de 0,378. Procedeu-se, então, a uma análise fatorial da escala excluindo o item 14, que resultou no aumento da variância explicada acumulada da escala para 48,98\%. O alpha de Cronbach do fator I com o item 14 era de 0,81 e com sua exclusão foi para 0,83 . A partir dessas duas evidências optoiu-se pela exclusão definitiva do item. 
$\mathrm{E}$, acompanhando os fundamentos teóricos da escala, optou-se pela definição de dois fatores. A análise restrita a duas dimensões fortaleceu o posicionamento dos itens 7 e 8 no segundo fator, obtendo-se, assim, índices adequados para a matriz.

O Fator 1 foi composto por sete itens relativos à autoabsorção privada, um a menos que na escala original. O Fator 2, composto por nove itens como na escala original, claramente referem ao conceito de autoabsorção pública. Obtiveram-se os valores alpha $=0,83$ para o Fator 1 e alpha $=0,84$ para o Fator 2, e ambos os resultados são considerados bastante satisfatórios. Na escala original em inglês, os índices de consistência encontrados haviam sido de 0,81 e 0,89 para os itens privados e públicos, respectivamente.

Para confirmar a matriz fatorial de cada uma das subescalas, conduziram-se suas respectivas análises fatoriais com método de extração por componentes principais com rotação Varimax. O KMO obtido para o Fator 1 (subescala de autoabsorção privada) foi de 0,877 . O scree plot evidenciou a distinção de apenas um fator, que explicou 52,09\% da variância da matriz. O KMO obtido para o Fator 2 (subescala de autoabsorção pública) foi de 0,866 , com a extração de dois fatores na primeira análise, com variância explicada de $57 \%$. Contudo, o scree plot sugeriu uma nova análise restrita a um fator. Neste caso, a variância explicada reduziu para 44,73\%, não prejudicando os índices da extração dos itens na composição do fator. Os resultados das análises de componentes principais podem ser acompanhados na Tabela 1. Evidencia-se nesta tabela que cada um dos itens apresentou cargas componenciais superiores a 0,35 exclusivamente no componente esperado, explicitando a coerência dos achados da escala com as expectativas teóricas.

\section{Evidências de validade convergente}

Ao se procederem análises correlacionais de Pearson entre as variáveis mensuradas pelas subescalas da EAA, EAC-R e QRR, pode-se compor o quadro de correlações ilustrado pela Tabela 2. Com base em Bisquerra, Sarriera e Martínez (2004), algumas correlações que merecem destaque por estarem consideradas em nossas hipóteses iniciais foram classificadas. Assim, observou-se uma correlação positiva alta $(r=$ $0,614, \mathrm{p}<0,001)$ entre autoabsorção pública e ruminação, e autoconsciência privada e reflexão $(r=0,631$, $\mathrm{p}<0,001)$. Correlações positivas moderadas foram observadas entre a variável autoabsorção pública e as variáveis autoabsorção privada $(r=0,500, \mathrm{p}<0,001)$, autoconsciência pública $(r=0,409$, p<0,001), e ansiedade social $(r=0,488, \mathrm{p}<0,001)$. Correlações positivas moderadas também foram encontradas entre as variáveis autoabsorção privada e ruminação $(r=$ $0,524, \mathrm{p}<0,001)$, as variáveis autoconsciência pública e autoconsciência privada $(r=0,432, \mathrm{p}<0,001)$, e ruminação e ansiedade social $(r=0,416, \mathrm{p}<0,001)$.

Tabela 2

Correlações entre Autoabsorção Privada, Autoabsorção Pública e Demais Variáveis

\begin{tabular}{lccccccc} 
Subescalas & $(1)$ & $(2)$ & $(3)$ & $(4)$ & $(5)$ & $(6)$ & $(7)$ \\
(1) Autoabsorção privada & - & & & & & & \\
(2) Autoabsorção pública &, $500^{*}$ & - & & & & & \\
(3) Autoconsciência privada &, $364^{*}$ &, $205^{*}$ & - & & & & \\
(4) Autoconsciência pública &, $191^{*}$ &, $409^{*}$ &, $432^{*}$ & - & & & \\
(5) Ansiedade social &, $272^{*}$ &, $488^{*}$ &, $146^{*}$ &, $198^{*}$ & - & & \\
(6) Ruminação &, $524^{*}$ &, $614^{*}$ &, $341^{*}$ &, $346^{*}$ &, $416^{*}$ & - & \\
(7) Reflexão &, $259^{*}$ &,- 029 &, $631^{*}$ &, $163^{*}$ &,- 026 &, 109 & - \\
\hline
\end{tabular}

Nota. ${ }^{*}$ Correlações de Pearson com $p<0,001$.

\section{DISCUSSÃO}

As análises estatísticas conduzidas evidenciaram a adequação da estrutura fatorial da versão brasileira em relação à escala original, confirmando a hipótese da divisão entre as dimensões pública e privada da autoabsorção. Em observação aos índices de consistência interna (alpha de Cronbach), os resultados foram mui- 
to satisfatórios, atingindo em ambas as subescalas valores semelhantes aos obtidos na escala original.

Em relação aos indícios de validade convergente da EAA, hipóteses foram criadas tendo como base as sugestões teóricas apresentadas pelos autores dos instrumentos utilizados neste estudo. Dessa forma, a subescala de autoabsorção pública da EAA deveria apresentar correlação positiva com as subescalas da EAC-R de autoconsciência pública e ansiedade social; ao passo que a subescala de autoabsorção privada da EAA deveria apresentar correlação positiva com a subescala de autoconsciência privada da EAC-R e o índice de ruminação do QRR.

De fato, conforme fora esperado, em comparação às subescalas da EAC-R, autoabsorção pública correlacionou-se de forma positiva e moderada com autoconsciência pública e de forma muito fraca em relação a autoconsciência privada. Já o fator autoabsorção privada correlacionou-se de maneira fraca com autoconsciência privada e muito fraca com relação a autoconsciência pública. A dimensão autoabsorção pública apresentou correlações mais elevadas do que autoabsorção privada em relação a ansiedade social. Esses dados sugerem uma congruência entre o que foi observado empiricamente e a teoria que relaciona as duas escalas às dimensões público e privado. Além disso, ao se observar a correlação muito baixa entre autoconsciência pública e ansiedade social, evidenciou-se empiricamente que a dimensão autoabsorção pública, ao apresentar correlações moderadas com ansiedade social, estaria distinguindo de forma mais precisa a faceta mal adaptativa da autoconsciência que pode evoluir para o surgimento de ansiedade social, segundo a explicação para a origem da ansiedade social de Fenigstein e cols. (1975).

Em comparação às subescalas do QRR, observouse que o fator ruminação correlacionou-se de maneira positiva, moderada e alta respectivamente com as subescalas de autoabsorção privada e pública. Esses achados também sugerem que a EAA reagiu de acordo com a teoria, ao se considerar que autoabsorção, enquanto uma faceta mal adaptativa da autoconsciência mantém semelhanças à definição de ruminação sugerida por Trapnell e Campbell (1999).

Sendo assim, os resultados obtidos com as análises correlacionais se mostraram de acordo com a teoria em relação à EAA. Contudo, os achados convergentes referentes ao QRR chamaram atenção dos autores desse estudo. Trapnell e Campbell (1999), ao lançarem o QRR, apresentaram-no como um desdobramento da subescala de autoconsciência privada da EAC-R. Os dados desta pesquisa revelaram que a subescala de "reflexão" do QRR de fato correlacionou-se positivamente apenas com a dimensão privada da autoconsciência da EAC-R. Contudo, a dimensão ruminação correlacionou-se de forma positiva e alta com autoabsorção pública e de forma positiva e moderada com todas as escalas da EAC-R, contradizendo a teoria dos autores do QRR. Este fato talvez possa ser explicado ao se investigar os itens do QRR: aventa-se a possibilidade da existência de uma ambiguidade no conteúdo proposto por alguns dos itens relativos a Ruminação do QRR. Ou seja, talvez a escala de ruminação do QRR contenha afirmativas em que fica aberta a possibilidade a cada respondente de imaginar ou remontar eventos públicos ou privados de sua vida no momento de responder ao item, descaracterizando a dimensão da ruminação. Os trabalhos de Papageorgiuou e Wells (2004) e DaSilveira (2007) sobre ruminação em resolução de problemas ressaltaram que aspectos da ruminação nem sempre estão relacionados a questões privadas do self. Mas, ao que consta no artigo de divulgação do QRR, os próprios autores referem-se ao fenômeno como autorruminação (do inglês, self-rumination), e explicitam que se trata de uma faceta derivada apenas da autoconsciência privada.

Em síntese, os achados desta pesquisa sugerem que estudos posteriores sejam feitos com o intuito de investigar a que eventos especificamente os participantes recorrem ao lerem os itens sugeridos no QRR, para fins de avaliar se a faceta Ruminação do QRR referese de fato tanto a aspectos privados quanto públicos da autoconsciência. Seria interessante também se observar se os achados presentes neste estudo se confirmam também na aplicação da EAA e do QRR em outras populações, com outros idiomas, por exemplo. Entende-se que a questão de Ruminação estar correlacionada a aspectos públicos pode indicar uma incongruência teórica na concepção do QRR por Trapnell e Campbell (1999), uma vez que os autores referem que o QRR fora criado como um refinamento apenas da dimensão privada da Escala de Autoconsciência de Fenigstein, Scheier e Buss (1975). Sendo assim, sugere-se que o uso da EAA seja privilegiado em alternativa ao QRR quando houver o interesse na distinção 
das dimensões pública e privada no contexto da reflexão individual má adaptativa. Já no caso de estudos em que o interesse dos pesquisadores resida no contraste entre aspectos adaptativos e mal adaptativos do foco da autoatenção, o QRR apresenta-se ainda como alternativa adequada ao que se propõe a medir.

Por fim, conclui-se que os objetivos de adaptação da EAA para adultos brasileiros foi atingido, obtendose evidências de validade e fidedignidade para as subescalas. Ainda assim, observam-se limitações da pesquisa: indícios de aplicabilidade em amostras da região norte e centro-oeste do país seriam importantes de ser coletados, dado que a representatividade dessas regiões fora inferior às demais regiões. De toda forma, entende-se que o instrumento já esteja em condições de uso em novos estudos. Sugere-se também a aplicação do instrumento em outras amostras controladas, por exemplo: amostras clínicas, como grupos com diagnóstico de depressão e ansiedade social.

\section{REFERÊNCIAS}

Aamodt, M. G., \& Keller, R. J. (1981). Using the self-consciousness scale to predict student discussion group participation. Teaching of Psychology, 8, 176-177.

Avsec, A., \& Bajec, B. (2006). Validation of the Slovene version of the self-consciousness scale. Horizons in Psychology, 15, 722.

Banos, R. M., Belloch, A., \& Perpina, C. (1990). Self-consciousness scale: A study of Spanish housewives. Psychological Reports, 66, 771-774.

Bisquerra, R., Sarriera, J. C., \& Martínez, F. (2004). Introdução à estatística: Enfoque informático com o pacote estatístico SPSS. Porto Alegre: Artmed.

Comunian, A. L. (1994). Self-consciousness scale dimensions: An Italian adaptation. Psychological Reports, 74, 483-123.

DaSilveira, A. C. (2007). Conversação interna: Entre a reflexividade e a ruminação. Dissertação de mestrado não-publicada, Universidade Federal do Rio Grande do Sul, Porto Alegre.

Dodge, S. C., Hope, D. A., Heimberg, R. G., \& Becker, R. E. (1988). Evaluation of the social interaction self-statement test with a social phobic population. Journal of Cognitive Therapy and Research, 12, 211-222.

Duval, T. S., \& Wicklund, R. A. (1972). A theory of objective self awareness. New York: Academic Press.

Edelmann, R. J. (1990). Chronic blushing, self-consciousness, and social anxiety. Journal of Psychopathology and Behavioral Assessment, 12, 119-127.

Fenigstein, A., Scheier, M. F., \& Buss, A. H. (1975). Public and private self-consciousness: Assessment and theory. Journal of Consulting and Clinical Psychology, 36, 1241-1250.
Gibbons, F. X. (1990). Self-attention and behavior: A review and theoretical update. Advances in Experimental Social Psychology, 23, 249-303.

Heinemann, W. (1979). The assessment of private and public selfconsciousness: A German replication. European Journal of Social Psychology, 9, 331-337.

Ingram, R. E. (1990). Self-focused attention in clinical disorders: Review and a conceptual model. Psychological Bulletin, 107, 156-176.

Jung, C. G. (1974). Tipos psicológicos (A. Cabral, Trad.). Rio de Janeiro: Zahar. (Original publicado em 1933)

McKenzie, K. S., \& Hoyle, R. H. (2008). The Self-Absorption Scale: Reliability and validity in non-clinical samples. Personality and Individual Differences, 45, 726-731.

Mead, G. H. (1962). Mind, self and society: From the standpoint of a social behaviorist. Chicago: University of Chicago Press. (Original publicado em 1934)

Mor, N., \& Winquist, J. (2002). Self-focused attention and negative affect: A meta-analysis. Psychological Bulletin, 128, 638662.

Nystedt, L., \& Smari, J. (1989). Assessment of the Fenigstein, Scheier and Buss self-consciousness scale: A Swedish translation. Journal of Personality and Assessment, 53, 342-352.

Papageorgiou, C., \& Wells, A. (2004). Nature, functions, and beliefs about depressive rumination. Em C. Papageorgiou \& A. Wells (Orgs.), Depressive rumination: Nature, theory, and treatment (pp. 3-20). West Sussex, England: Wiley.

Realo, A., \& Allik, J. (1998). The Estonian Self-Consciousness Scale and its relation to the five-factor model of personality. Journal of Personality Assessment, 70, 109-124.

Robinson, J. C., Hobbs, T. B., Joseph, N., Robertson, J., \& Singleton, G. (2000). Preliminary findings on African American teachers' African self-consciousness and student perceptions. The Journal of Multiculturalism in Education, 3, 1-27. Retirado de http://www.multiculturaljournal.com/volumes/3/afri can_american_teachers.pdf

Ruganci, N. (1995). Private and public self-consciousness subscales of the Fenigstein, Scheier and Buss self-consciousness scale: A Turkish translation. Personality and Individual Differences, 18, 279-282.

Ruipérez, M. A., \& Belloch, A. (2003). Dimensions of the selfconsciousness scale and their relationship with psychopathological indicators. Journal of Personality and Individual Differences, 35, 829-841.

Scandell, D. J. (2001). Is self-reflectiveness an unhealthy aspect of private self-consciousness? The Journal of Psychology, 135, 451-461.

Scheier, M. F., \& Carver, S. C. (1985). The self-consciousness scale: A revised version for use with general populations. Journal of Applied Social Psychology, 15, 687-699.

Shek, D. T. L. (1994). Assessment of private and public selfconsciousness: A Chinese replication. Journal of Clinical Psychology, 50, 341-348. 
Striegel-Moore, R. H., Silberstein, L. R., \& Rodin, J. (1993). The social self in bulimia nervosa: Public self-consciousness, social anxiety, and perceived fraudulence. Journal of Abnormal Psychology, 102, 297-303.

Teixeira, M. A. P., \& Gomes, W. B. (1995). Self-Consciousness Scale: A Brazilian version. Psychological Reports, 77, 423-427.

Trapnell, P. D., \& Campbell, J. D. (1999). Private selfconsciousness and the five-factor model of personality: Distinguishing rumination from reflection. Journal of Personality and Social Psychology, 76, 284-304.

Watson, P. J., Hickman, S. E., Morris, R. J., Stutz, N. L., \& Whiting, L. (1994). Complexity of self-consciousness subscales: Corre- lations of factors with self-esteem and dietary restraint. Journal of Social Behavior and Personality, 9, 761-774.

Zanon, C., \& Teixeira, M. A. P. (2006). Adaptação do Questionário de Ruminação e Reflexão (QRR) para estudantes universitários brasileiros. Interação em Psicologia, 10, 75-82.

Recebido: 11/05/2010 Última revisão: 19/11/2010 Aceite final: 15/12/2010 